\title{
$\mathrm{CO}_{2}$ 배관의 연속연성파괴 분석
}

\author{
정효태 · ${ }^{\dagger}$ 최병학 · 김우식* - 백종현* \\ 강릉원주대학교 신소재금속공학과, *한국가스공사 연구개발원 \\ (2014년 4월 21일 접수, 2014년 6월 5일 수정, 2014년 6월 5일 채택)
}

\section{Analysis on Dynamic Ductile Fracture of Transportation Pipeline for Carbon Dioxide Capture and Storage System}

\author{
Hyo-Tae Jeong · ${ }^{\dagger}$ Byung-Hak Choe • Woo-Sik Kim* • Jong-Hyeon Baek* \\ Dept. of Advanced Metal \& Materials Engineering, Gangneung-Wonju National University, \\ Gangneung 210-702, Korea \\ *Korea Gas R\&D Division, Ansan 638-1, Korea \\ (Received April 21, 2014; Revised June 5, 2014; Accepted June 5, 2014)
}

요 약

이산화탄소 포집 및 저장 시스템(CCS, Carbon dioxide Capture and Storage system)의 수송배관에 대한 연속연성파괴(DDF, Dynamic Ductile Fracture)를 연구하기 위하여 Battlle Two Curve법(BTCM)으로 CCS수 송배관의 연속연성파괴거동을 해석하여 천연가스 수송배관의 연속연성파괴거동과 비교하였다. 또한, $\mathrm{CO}_{2}$ 배관에서의 배관두께 및 사용온도에 따른 연속연성파괴 민감도를 분석함으로써 연속연성파괴에 대한 사용 기준을 해석하였다. 우리나라 기후조건에 따른 $\mathrm{CO}_{2}$ 배관두께와 수송압력 사용기준을 분석하였으며, 상온의 경우에는 기존의 천연가스용 배관을 $\mathrm{CO}_{2}$ 배관으로 사용하기 위해서는 배관두께가 $7 \mathrm{~mm}$ 이상이어야 하고 수 송압력은 $54 \mathrm{bar}$ 이하이어야 함을 해석하였다.

Abstract - Dynamic ductile fracture (DDF) has been studied in the transportation pipeline for the carbon dioxide capture and storage(CCS) system. DDF behavior of CCS transportation pipeline has been analyzed using Battelle Two Curve Method (BTCM) and compared with the DDF behavior of natural gas pipeline. The operating safety criteria against the DDF has been investigated based on the sensitivity analyses of the pipe thickness and the operating temperature for the $\mathrm{CO}_{2}$ pipeline. The DDF criteria can be applied to confirm the operating safety of the $\mathrm{CO}_{2}$ pipeline. If the commercial natural gas pipeline were used at room temperature as a $\mathrm{CO}_{2}$ pipeline, the thickness of pipe should be at least $7 \mathrm{~mm}$ and the pressure should be less than $54 \mathrm{bar}$ for the $\mathrm{CO}_{2}$ pipeline system.

Key words : Dynamic Ductile Fracture, CCS, Carbon Dioxide, Battle Two Curve Method

${ }^{\dagger}$ Corresponding author:cbh@gwnu.ac.kr

Copyright (c) 2014 by The Korean Institute of Gas 


\section{I. 서 론}

CCS (Carbon Dioxide Capture and Storage)란 화력발전 및 석유-화학 플랜트로부터 배출되는 이 산화탄소를 포집하고 저장하는 시스템을 일컫는다. 또한 CCS 수송배관이란 포집된 이산화탄소를 저장 장소까지 이송하는 배관이다. 그런데 아직까지 $\mathrm{CO}_{2}$ 수송의 전용 배관은 없으며, 현재 사용 중인 가스배 관을 이것에 적용하려는 시도가 미국 등 기술선진국 에서 시도되고 있다. 그러나 이 경우 10 기압 미만의 저압인 $100 \%$ 의 고순도 $\mathrm{CO}_{2}$ 가 적용되므로 현실적인 고압과 불순물을 포함한 $\mathrm{CO}_{2}$ 분위기를 고려하지는 못하는 상황이다[1,2].

연속연성파괴(Dynamic Ductile Fracture, 이하 $\mathrm{DDF}$ )란 사용압력이 존재하는 배관이 경우에 따라 서는 수 $\mathrm{km}$ 에 이르는 상당히 긴 구간에 걸쳐 파열이 연속으로 진전되는 파단을 일컫는다. $\mathrm{DDF}$ 는 사용 내부압력(p)이 배관 파열에 의해 감소되는 압력감소 속도 $\left(\mathrm{V}_{\mathrm{p}}\right)$ 와 배관파열진전속도 $\left(\mathrm{V}_{\mathrm{f}}\right)$ 의 상대적인 속도 차이에 의해 발생되는 데, 압력감소속도 $\left(\mathrm{V}_{\mathrm{p}}\right)$ 가 파열 진전속도 $\left(\mathrm{V}_{\mathrm{f}}\right)$ 보다 적은 경우 $\left(\mathrm{V}_{\mathrm{p}}<\mathrm{V}_{\mathrm{f}}\right)$, 배관파열진행 선단의 내부압력의 감소가 충분하지 않으므로 배관 의 파열은 리크시작 위치로부터 양방향으로 발생된 다. 파열은 두 속도가 같아지는 시점인 $\mathrm{V}_{\mathrm{p}}=\mathrm{V}_{\mathrm{f}}$ 까지 계속되다가 멈추는데, 이때 파단형태는 연성파단이 다[3,4].

$\mathrm{DDF}$ 가 보고된 것은 1970 년대로 당시 가스배관 파열이 수백m에 이르는 대형 사고를 동반 하였다. Fig. 1은 DDF 사고 사례를 보여주는 것이다[3]. 이에 따라 영국, 미국, 캐나다, 일본 등 기술선진국에서는 $\mathrm{DDF}$ 를 방지할 코드를 마련하였고, 지금은 $\mathrm{DDF}$ 기 본코드와 재질 설계기준이 마련되어 선진 개발국에 서는 이를 공동사용 중이다[5-9].

배출가스를 포함하는 $\mathrm{CO}_{2}$ 배관은 천연가스 배관 에 비해 부식 위험성이 크다. 따라서 $\mathrm{CO}_{2}$ 배관은 부 식 피트 리크에 의한 $\mathrm{DDF}$ 설계코드가 적용되어야 한다. 지금까지 $\mathrm{CO}_{2}$ 배관의 $\mathrm{DDF}$ 관련 연구는 거의
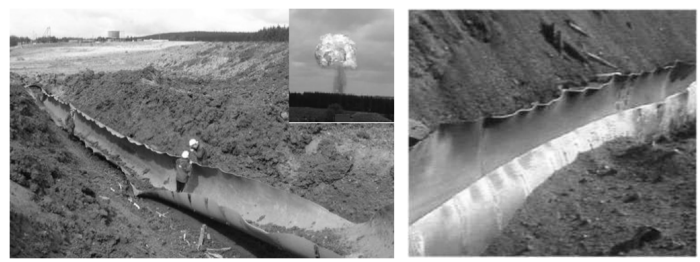

Fig. 1. Photos showing a dynamic ductile fracture[3].
없다. 본 연구에서는 가스배관에 적용된 $\mathrm{DDF}$ 코드 를 기준으로 CCS 배관 $\mathrm{DDF}$ 를 파악하고자 하였다. 가까운 미래에 $\mathrm{CO}_{2}$ 배관은 중요한 플랜트 산업으로 자리할 것이다. 본 연구를 통하여 가스배관 재질을 이용하는 $\mathrm{CO}_{2}$ 배관의 $\mathrm{DDF}$ 방지 설계기술이 확보될 수 있고, 이것의 건전한 사용을 꾀할 수 있다.

\section{II. 실험방법}

$\mathrm{CO}_{2}$ 배관의 $\mathrm{DDF}$ 관계식은 배관파열진전속도와 압력감소속도의 계산결과를 비교하여 이루어지는데, 배관파열진전속도는 가스배관 재질 사용을 기본으 로 하고, 압력감소속도는 배관내부 사용가스인 이산 화탄소의 물성을 기본으로 한다.

$\mathrm{DDF}$ 기준 관계식에 포함되는 재질특성 값은 항복 강도(유동응력), 탄성계수 및 충격흡수 에너지(Charpy V-notched energy 이하 CVN)이다. 또한 가스배 관 반경 및 배관 두께, 가스 배관 사용조건인 사용압 력과 사용가스에서의 음속 및 배관이 묻힌 상태에 대한 backfill 계수가 적용된다.

본 연구에서는 X65 및 X70 Grade의 가스 배관에 대한 $\mathrm{DDF}$ 를 파악하고자 하여, $\mathrm{X} 65$ 및 X70 배관의 각 항복강도, 탄성계수와 $\mathrm{CVN}$ 및 각 배관의 직경과 두 께가 변수로 대입된다. 그런데 두 종류 가스배관에 있어서 현장에 설치 된 모든 조건을 망라하여 $\mathrm{DDF}$ 판정을 마련하는데, 여기에는 배관의 용접부/모재, 배 관방향 (Long, 45 도, Trans), 사용온도 $\left(20^{\circ} \mathrm{C} \sim-40^{\circ} \mathrm{C}\right)$, 용접 종류 (자동 및 수동), 연간밴드(인장, 압축, 미 변형) 조건에서 얻어지는 CVN 값이 주요변수로 적 용 된다. 본 연구에서 $\mathrm{DDF}$ 관계식은 Excel 코드로 작성되었으며, 입력 값은 Excel data로 입력된다.

\section{III. 이론적 배경}

Battelle Two-Curve Method(BTCM)란 가스 배관 의 파단속도(Fracture velocity, $\mathrm{V}_{\mathrm{f}}$ )와 사용가스 압력 의 감압속도(Decompression Velocity, $\mathrm{V}_{\mathrm{p}}$ )를 비교하 여, $\mathrm{DDF}$ 유무를 판정하는 기준식이다. 즉 가스 사용 압력(p)에서 $\mathrm{V}_{\mathrm{f}}>\mathrm{V}_{\mathrm{p}}$ 인 경우 균열 첨단은 항상 동일한 응력상태이며 연속적인 파단이 야기된다[1,2]. 그러 므로, $\mathrm{V}_{\mathrm{f}}=\mathrm{V}_{\mathrm{p}}$ 를 이루는 지점이 배관이 가져야 하는 최소의 재질인성이 된다. 이러한 인성 값은 충격에 너지(CVN) 또는 DWTT(Drop weight Tearing test) 값으로 정해진다.

Fig. 2 를 살펴보면 어느 지점의 배관 내부압력 $\left(\mathrm{P}_{\mathrm{d}}\right)$ 에 대해서 배관파열진전속도 $\left(\mathrm{V}_{\mathrm{f}}\right)$ 및 압력감소속도 $\left(\mathrm{V}_{\mathrm{p}}\right)$ 가 각각 구해질 수 있음을 알 수 있다. (즉, $\mathrm{y}$ 축 $\left(\mathrm{P}_{\mathrm{d}}\right)$ 한 


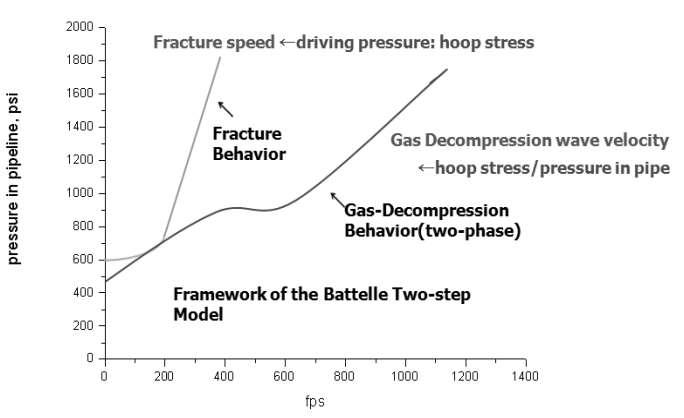

Fig. 2. A schematic diagram showing the fracture behavior and gas decompression behavior in Battelle's two curve method[4].

지점에서 수평으로 선을 그으면 $\mathrm{V}_{\mathrm{f}}$ 및 $\mathrm{V}_{\mathrm{p}}$ 곡선과 만 나는 점을 구할 수 있다.) 이때 $\mathrm{V}_{\mathrm{p}}<\mathrm{V}_{\mathrm{f}}$ 라면, 파열속 도가 압력감소속도보다 크기 때문에 균열은 계속 진 전하게 된다. 따라서 $\mathrm{V}_{\mathrm{p}} \leqq \mathrm{V}_{\mathrm{f}}$ 관계식을 기준으로 하 여 $\mathrm{DDF}$ 를 판정하는 것이다. 이것을 $\mathrm{BCTM}$ (Battelle Two Curve Method)이라고 한다[4].

Battelle Two-Curve Method (BTCM)의 배관 파 단속도 $\left(\mathrm{V}_{\mathrm{f}}\right)$ 와 가스감압속도 $\left(\mathrm{V}_{\mathrm{p}}\right)$ 는 다음 두 식 으로 규정된다. 아래 식(1)에서 파열진전속도 $\left(\mathrm{V}_{\mathrm{f}}\right)$ 는 배관 재질에 관련한다. 여기에 포함된 변수의 영향성을 평가하면 다음과 같다.

(1) $\mathrm{C}_{\mathrm{B}}$ (backfill constant)가 클수록 $\mathrm{V}_{\mathrm{f}}$ 증가: 이것 은 배관을 덮은 모양이 무거울수록 $\mathrm{V}_{\mathrm{f}}$ 가 증가 하는 것을 의미한다.

(2) $\sigma_{\mathrm{f}}$ (flow stress)가 클수록 $\mathrm{V}_{\mathrm{f}}$ 증가: 이것은 배관 재질의 항복강도가 클수록 $\mathrm{V}_{\mathrm{f}}$ 가 증가하는 것 을 의미한다.

(3) CVP (charpy energy)가 클수록 $\mathrm{V}_{\mathrm{f}}$ 감소: 이것 은 배관 재질의 인성이 클수록 $\mathrm{V}_{\mathrm{f}}$ 가 감소하는 것을 의미한다.

(4) $\sigma_{d}$ (decompressed hoop stress, $P_{d} \cdot R_{m} / t$ )가 클수록 $\mathrm{V}_{\mathrm{f}}$ 증가: 이것은 배관 형상에서 배관 반지름이 클수록 또한 배관두께가 작을수록 $\mathrm{V}_{\mathrm{f}}$ 가 증가하는 것을 의미한다.

또한 아래 식 (3)에서 압력감소속도 $\left(\mathrm{V}_{\mathrm{p}}\right)$ 는 이산화 탄소 물성에 관련한다. 여기에 포함된 변수의 영향 성을 평가하면 다음과 같다.

(1) $\mathrm{V}_{\mathrm{a}}\left(\mathrm{CO}_{2}\right.$ 내에서 음속 $)$ 가 클수록 $\mathrm{V}_{\mathrm{p}}$ 증가: 이것 은 $\mathrm{CO}_{2}$ 내의 음속이 증가할수록 가스 확산 방 출이 크며 $\mathrm{V}_{\mathrm{p}}$ 가 증가하는 것을 의미한다.

(2) $\mathrm{\gamma}\left(\mathrm{CO}_{2}\right.$ 의 비열비 $)$ 의 $\mathrm{V}_{\mathrm{p}}$ 영향성: 이것은 가스의 비열이 $\mathrm{V}_{\mathrm{p}}$ 에 영향을 주는 것을 의미한다.
(3) $\mathrm{P}_{\mathrm{i}}$ 가스사용압력)가 클수록 $\mathrm{V}_{\mathrm{p}}$ 감소: 이것은 가스 사용압력이 크면 $\mathrm{V}_{\mathrm{p}}$ 가 감소하는 것을 의미한다.

$$
V_{f}=\left[\frac{C_{B} \sigma_{f}}{\sqrt{C V P \sigma}}\right]\left[\frac{\sigma_{d}}{\sigma_{a}}-1\right]^{1 / 6}
$$

where

$\mathrm{V}_{\mathrm{f}}=$ fracture speed, $\mathrm{m} / \mathrm{s}$

$C_{B}=$ backfill constant backfill constant $(2.76$ for no Backfill, 2.00 for soil backfilled and 1.71 for water backfilled pipe)

$\sigma_{\mathrm{f}}=$ flow stress, $\mathrm{MPa}$

$\mathrm{CVP}=$ Charpy V-notch upper-shelf energy for a 2/3 Thickness specimen, $\mathrm{J}$

$\sigma_{\mathrm{d}}=$ decompressed hoop stress $\left(\sigma_{\mathrm{d}}=\mathrm{P}_{\mathrm{d}} \mathrm{R}_{\mathrm{m}} / \mathrm{t}\right)$, $\mathrm{MPa}$

$\sigma_{\mathrm{a}}=$ arrest stress, $\mathrm{MPa}$

$\mathrm{P}_{\mathrm{d}}=$ decompressed pressure, $\mathrm{MPa}$

$\mathrm{R}_{\mathrm{m}}=$ mean pipe radius, $\mathrm{mm}$

$\mathrm{t}$ = pipe or tube thickness, $\mathrm{mm}$

with

$\sigma_{a}=$

$\frac{2 \sigma_{f}}{3.333 \pi} \arccos \left(\exp \left[\frac{18.75 \times C V P \times E \times \pi}{24 \sigma_{f}^{2}\left(R_{m} t\right)^{0.6}}\right]\right)$

and

$\mathrm{E}=$ elastic modulus, $\mathrm{MPa}$.

$P_{d}=P_{i}\left[\frac{2}{\gamma+1}+\left(\frac{\gamma-1}{\gamma+1}\right) \frac{V}{V_{a}}\right]^{\frac{2 \gamma}{\gamma-1}}$

where

$\mathrm{P}_{\mathrm{d}}$ is a given decompressed pressure level, in ksi or MPa

$P_{\mathrm{i}}$ is the initial line pressure prior to rupture, in ksi or MPa

$\mathrm{V}$ is the pressure wave velocity (propagation velocity for a given decompressed pressure level), in feet per second or meters per second.

$\mathrm{V}_{\mathrm{a}}$ is the acoustic velocity in the gas at its initial pressure and temperature, in feet per second or meters per second.

$\gamma$ is the initial specific heat ratio of the gas.

$\mathrm{DDF}$ 의 기준은 이와 같은 식(1)의 $\mathrm{V}_{\mathrm{f}}$ 와 식(3)의 $\mathrm{V}_{\mathrm{p}}$ 를 비교함으로써 구해진다. 즉 $\mathrm{V}_{\mathrm{p}}<\mathrm{V}_{\mathrm{f}}$ 이면 연속 파단조건이며, $\mathrm{V}_{\mathrm{p}}>\mathrm{V}_{\mathrm{f}}$ 이면 파단정지조건을 의미하 
는 것이다. 그런데 $\mathrm{V}_{\mathrm{f}}$ 와 $\mathrm{V}_{\mathrm{p}}$ 는 모두 가스누출에 의한 압력감소 한 시점의 압력인 $\mathrm{P}_{\mathrm{d}}$ (decompressed pressure)로 구해진다. $\mathrm{P}_{\mathrm{d}}$ 는 $\mathrm{V}_{\mathrm{p}}$ 에 직접 입력되지만 $\mathrm{V}_{\mathrm{f}}$ 에는 후프응력으로 환산되어 입력된다. $\left(\sigma_{\mathrm{d}}=\mathrm{P}\right.$ $\left.\mathrm{d} \cdot \mathrm{R}_{\mathrm{m}} / \mathrm{t}\right)$.

\section{IV. 결과 및 고찰}

\section{1. $\mathrm{CO}_{2}$ 배관에 대한 기존 $\mathrm{CH}_{4}$ 가스배관 적 용성 평가}

여기에서는 $\mathrm{CO}_{2}$ 배관을 기존의 가스배관을 사용 한다고 가정하였을 때 $\mathrm{DDF}$ 의 발생을 계산하고자 한다. 먼저 파열진전속도 $\left(\mathrm{V}_{\mathrm{f}}\right)$ 계산에 입력되는 배관 재질상수 값은 아래와 같으며, 분위기에 따른 차이 는 없다고 가정하였다.

(1) $\mathrm{C}_{\mathrm{B}}=2.0$ (at soil)

(2) $\sigma_{\mathrm{f}}=\sigma_{\mathrm{ys}}+10 \mathrm{ksi}=65 \mathrm{ksi}+10 \mathrm{ksi}=517.5 \mathrm{MPa}$

(3) $\mathrm{CVN}=3.949 \mathrm{MJ} / \mathrm{m}^{2}$

(4) $\sigma_{\mathrm{a}}=92.88\left(\mathrm{E}: 200 \mathrm{GPa}, \mathrm{R}_{\mathrm{m}}=762, \mathrm{~T}=\right.$ $17.5 \mathrm{~mm})$

(5) $P_{a}=\sigma_{a} \times \frac{t}{R_{m}}=2.1333$

또한 $\mathrm{CO}_{2}$ 가스를 기준으로 하여 가스압력 감소속 도 $\left(\mathrm{V}_{\mathrm{p}}\right)$ 계산에 입력되는 가스상수는 아래와 같다.

- 사용압력 $=70 \mathrm{bar}$

- 초기음속 $=395.8^{\mathrm{m} / \mathrm{s}}\left(20^{\circ} \mathrm{C}\right)$

$\cdot \mathrm{y}=\frac{C p}{C v}=3.395\left(20^{\circ} \mathrm{C}\right)$

이와 같이 구해진 가스 압력감소속도 $\left(\mathrm{V}_{\mathrm{p}}\right)$ 와 배관 파열진전속도 $\left(\mathrm{V}_{\mathrm{f}}\right)$ 를 비교하면 Fig. 3과 같다. 그림은 반지름이 $381 \mathrm{~mm}$, 두께가 $15.9 \mathrm{~mm}$ 인 X70 등급 가스배 관에 사용되는 기존 천연가스 $\left(\mathrm{CH}_{4}\right)$ 와 가상 적용의 $\mathrm{CO}_{2}$ 를 비교한 것인데, 가스 사용조건은 모두 70 기 압, $20^{\circ} \mathrm{C}$ 이다.

그림에서 메탄가스는 $\mathrm{V}_{\mathrm{p}} \doteqdot \mathrm{V}_{\mathrm{f}}$ 로 $\mathrm{DDF}$ 경계조건 이지만, $\mathrm{CO}_{2}$ 가스는 $\mathrm{V}_{\mathrm{p}}>\mathrm{V}_{\mathrm{f}}$ 로 $\mathrm{DDF}$ 가 발생하지 않 은 것이 확인된다. 즉 같은 배관 및 사용조건에서 이 산화탄소는 메탄보다 $\mathrm{DDF}$ 에 안정적인 사용을 할 수 있는 것을 알 수 있다.

\section{2. 배관두께 민감도}

$\mathrm{CO}_{2}$ 배관으로 반지름 $381 \mathrm{~mm}$ 인 X70 등급 가스배 관을 사용한다고 했을 때, 배관두께가 어느 정도까 지 얇아도 $\mathrm{DDF}$ 에 안정한지 평가하여 보았다. Fig. 4 는 배관 두께를 $8 \mathrm{~mm}$ 로 가정하였을 때 70 기압, $20^{\circ} \mathrm{C}$ 에서 $\mathrm{CH}_{4}$ 와 $\mathrm{CO}_{2}$ 에 대한 계산결과이다.

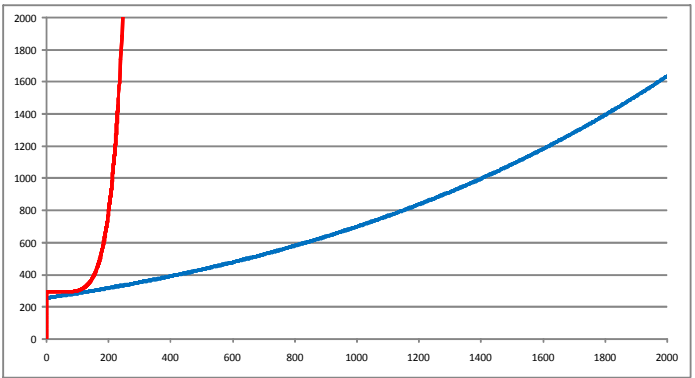

(a) $\mathrm{CH}_{4}$

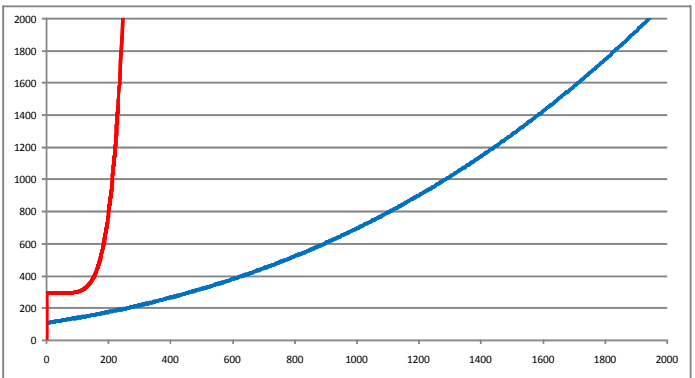

(b) $\mathrm{CO}_{2}$

Fig. 3. DDF Criteria of (a) $\mathrm{CH}_{4}$ and (b) $\mathrm{CO}_{2}$ at $70 \mathrm{bar}$ and $20^{\circ} \mathrm{C}$ with $15.9 \mathrm{~mm}$ thick $\mathrm{X} 70$ pipe.

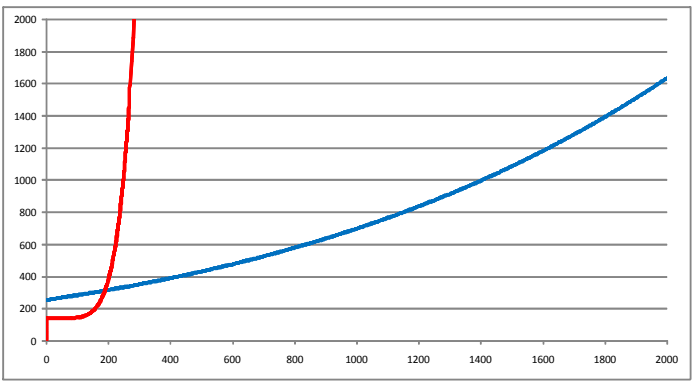

(a) $\mathrm{CH}_{4}$

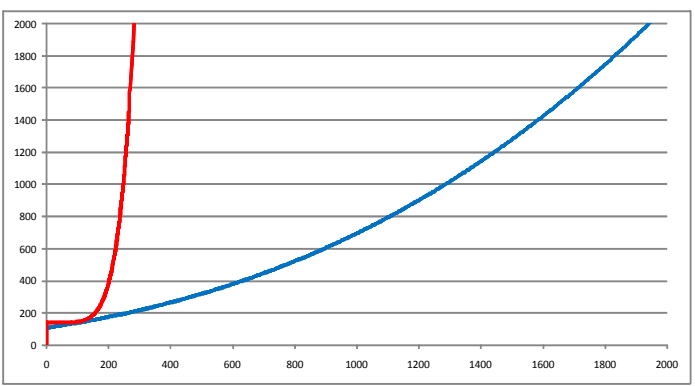

(b) $\mathrm{CO}_{2}$

Fig. 4. DDF Criteria of (a) $\mathrm{CH}_{4}$ and (b) $\mathrm{CO}_{2}$ at 70 bar and $20^{\circ} \mathrm{C}$ with $8 \mathrm{~mm}$ thick $\mathrm{X} 70$ pipe. 
Fig. 4(a)에서 $\mathrm{CH}_{4}$ 의 경우는 배관두께 $8 \mathrm{~mm}$ 에 대해 $\mathrm{V}_{\mathrm{p}}<\mathrm{V}_{\mathrm{f}}$ 영역이 존재하여 $\mathrm{DDF}$ 가 초래되는 것을 알 수 있는데, Fig. 4(b)의 $\mathrm{CO}_{2}$ 사용조건에서는 $\mathrm{V}_{\mathrm{p}} \geqq \mathrm{V}_{\mathrm{f}}$ 결과로 $\mathrm{DDF}$ 가 발생하지 않는 것을 알 수 있다.

\section{3. 사용온도 민감도}

$\mathrm{CO}_{2}$ 수송라인에 X70 등급의 기존 가스배관을 사 용함을 가정하는 경우, 사용온도의 민감도를 평가하 였다. 여기에서 배관 형상은 반지름 $381 \mathrm{~mm}$, 두께 $11.1 \mathrm{~mm}$ 가정하였는데, 이것은 기존 배관의 제조 규격 중 하나로 $20^{\circ} \mathrm{C}, 70$ 기압의 $\mathrm{CO}_{2}$ 사용조건에서는 $\mathrm{DDF}$ 가 발생하지 않는 배관 규격이다. 표 1 은 $\mathrm{CO}_{2}$ 가 적용된 X70 배관의 $\mathrm{DDF}$ 계산을 위한 사용온도별 물성이다.

Fig. 5 는 $\mathrm{CO}_{2}$ 배관으로 반지름 $381 \mathrm{~mm}$, 두께 $11.1 \mathrm{~mm}$ 인 기존의 X70 배관을 사용하였을 때 사용온도가 각 각 $20^{\circ} \mathrm{C}, 0^{\circ} \mathrm{C},-20^{\circ} \mathrm{C},-40^{\circ} \mathrm{C}$ 인 경우에 대해 $\mathrm{DDF}$ 를 판 정한 것이다. 그림에서 $\mathrm{X} 70$ 배관은 $0{ }^{\circ} \mathrm{C}$ 까지 $\mathrm{DDF}$ 위험성이 없지만 $-20^{\circ} \mathrm{C}$ 이하 온도에서 $\mathrm{DDF}$ 발생 가 능성이 있는 것을 알 수 있다. 단 아래 결과는 모든 온도와 압력의 계산 조건에서 $\mathrm{CO}_{2}$ 가 기체 상태임을 가정한 것이다.

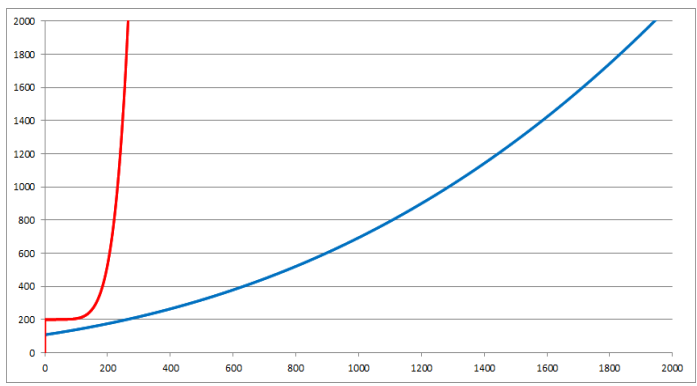

(a) $20^{\circ} \mathrm{C}$

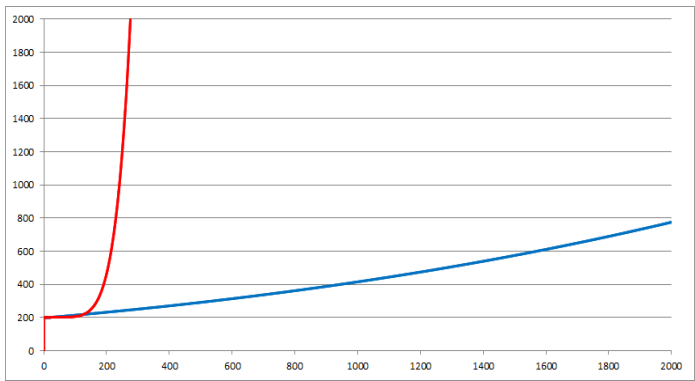

(c) $-20^{\circ} \mathrm{C}$
4.4. 우리나라 배관 사용조건(온도, 압력)에서의 $\mathrm{DDF}$ 저항 배관두께 기준 설정

앞 절까지는 $\mathrm{CO}_{2}$ 배관을 $\mathrm{CH}_{4}$ 배관과 비교하기 위 하여 $\mathrm{CH}_{4}$ 배관사용조건과 동일하게 하여 비교하였 으나, $\mathrm{CO}_{2}$ 는 $\mathrm{CH}_{4}$ 배관 사용조건의 온도와 압력에서 는 액체 상태로 존재하므로, $\mathrm{CO}_{2}$ 는 $20^{\circ} \mathrm{C}$ 에서 $70 \mathrm{bar}$ 의 압력을 사용할 수 없다. 그러므로 $\mathrm{CO}_{2}$ 배관 사용 조건으로는 $\mathrm{CO}_{2}$ 상태도상에서 주어진 사용 온도에 서 $\mathrm{CO}_{2}$ 가 기체 상태로 존재하는 압력조건을 각 온 도의 최대압력에서 약 1 2기압정도 낮은 압력으로

Table 1. Physical properties of $\mathrm{CO}_{2}$ and $\mathrm{X} 70 \mathrm{de}-$ pending on temperatures

\begin{tabular}{|c|c|c|c|}
\hline Temp. & $\begin{array}{c}\text { Sound } \\
\text { speed }\end{array}$ & $\begin{array}{c}\text { Specific } \\
\text { heat ratio }\end{array}$ & $\begin{array}{c}\text { Charpy } \\
\text { impact energy }\end{array}$ \\
\hline \hline $20^{\circ} \mathrm{C}$ & 395.8 & 3.395 & 387.3 \\
\hline $0^{\circ} \mathrm{C}$ & 599.4 & 2.470 & 376.3 \\
\hline$-20^{\circ} \mathrm{C}$ & 756.6 & 2.0192 & 357.5 \\
\hline$-40^{\circ} \mathrm{C}$ & 898.5 & 2.036 & 365.1 \\
\hline
\end{tabular}

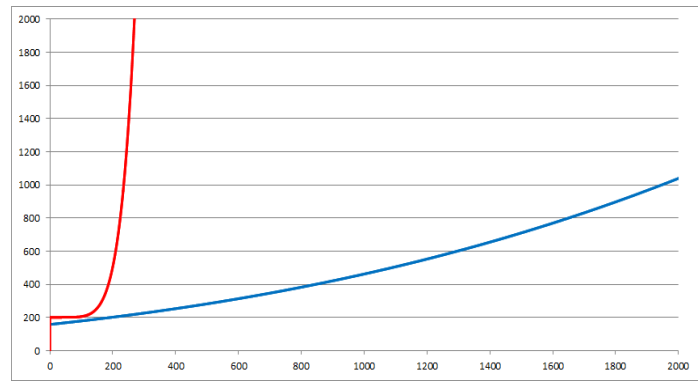

(b) $0^{\circ} \mathrm{C}$

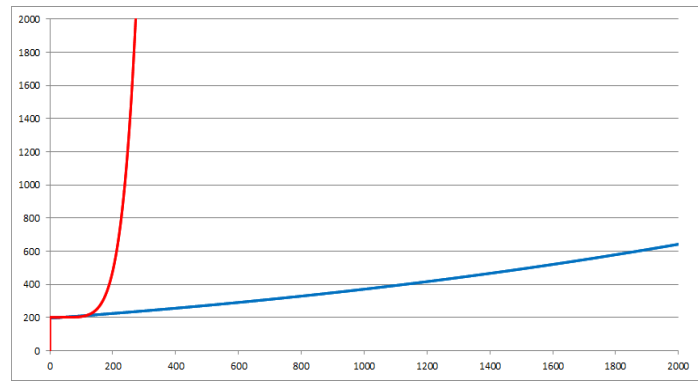

(d) $-40^{\circ} \mathrm{C}$

Fig. 5. DDF Criteria of $\mathrm{CO}_{2}$ at $70 \mathrm{bar}$ and (a) $20^{\circ} \mathrm{C}$, (b) $0^{\circ} \mathrm{C}$, (c) $-20^{\circ} \mathrm{C}$ and (d) $-40^{\circ} \mathrm{C}$ with $11.1 \mathrm{~mm}$ thick X70 pipe. 


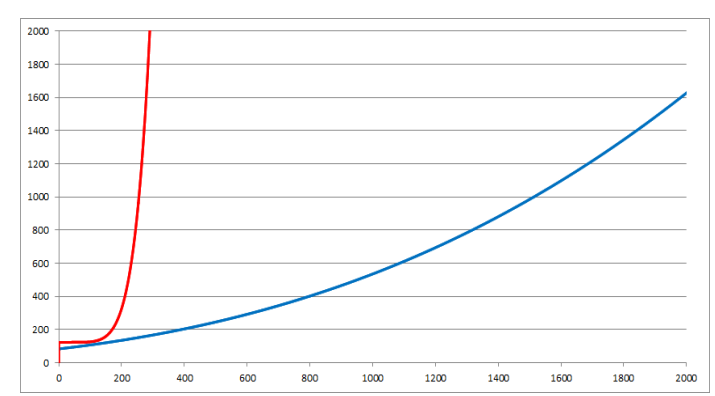

(a) $20^{\circ} \mathrm{C}$

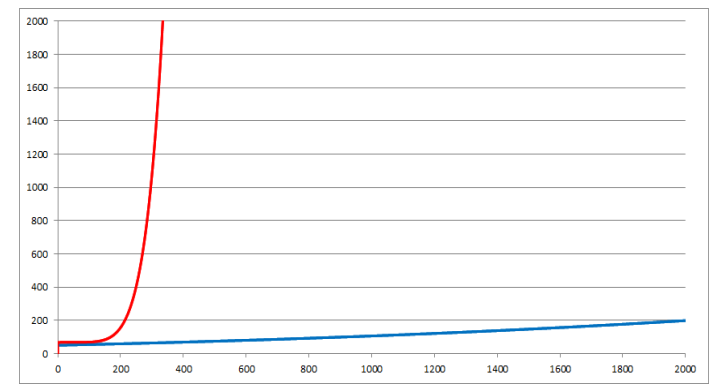

(c) $-20^{\circ} \mathrm{C}$

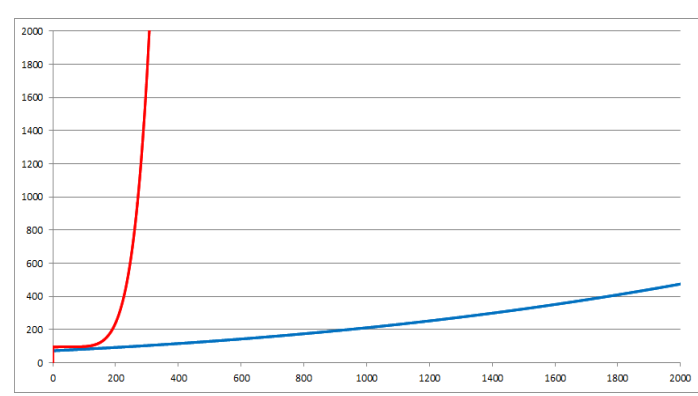

(b) $0^{\circ} \mathrm{C}$

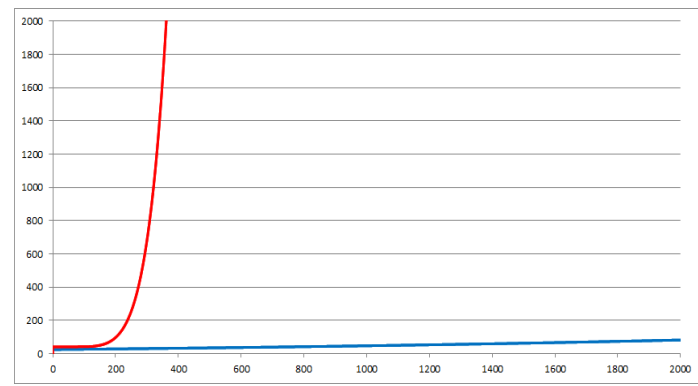

(d) $-40^{\circ} \mathrm{C}$

Fig. 6. DDF Criteria of $\mathrm{CO}_{2}$ at (a) $20^{\circ} \mathrm{C} / 54 \mathrm{bar}$, (b) $0^{\circ} \mathrm{C} / 32 \mathrm{bar}$, (c) $-20^{\circ} \mathrm{C} / 18 \mathrm{bar}$ and (d) $-40^{\circ} \mathrm{C} / 9 \mathrm{bar}$ with $\mathrm{X} 70$ pipe of $381 \mathrm{~mm}$ radius.

Table 2. Physical properties of $\mathrm{CO}_{2}$ and $\mathrm{X} 70$ depending on temperatures

\begin{tabular}{|c|c|c|c|c|}
\hline Temp. & $\begin{array}{c}\text { Pressure } \\
\text { (bar) }\end{array}$ & $\begin{array}{c}\text { Sound } \\
\text { speed }\end{array}$ & $\begin{array}{c}\text { Charpy } \\
\text { impact } \\
\text { energy }\end{array}$ & $\begin{array}{c}\text { Minimum } \\
\text { Thickness }\end{array}$ \\
\hline \hline $20^{\circ} \mathrm{C}$ & 54 & 395.8 & 387.3 & $7.0 \mathrm{~mm}$ \\
\hline $0^{\circ} \mathrm{C}$ & 32 & 599.4 & 376.3 & $5.5 \mathrm{~mm}$ \\
\hline$-20^{\circ} \mathrm{C}$ & 18 & 756.6 & 357.5 & $4.0 \mathrm{~mm}$ \\
\hline$-40^{\circ} \mathrm{C}$ & 9 & 898.5 & 365.1 & $2.5 \mathrm{~mm}$ \\
\hline
\end{tabular}

$\mathrm{CO}_{2}$ 수송을 $20^{\circ} \mathrm{C}$ 에서 한다면, 54 기압까지 압력을 사용할 수 있으며 이러한 사용조건으로 하는 경우 배관 최저 두께는 $7.0 \mathrm{~mm}$ 이다. 그러나, 우리나라 기 후의 $-40^{\circ} \mathrm{C}$ 최저 온도를 감안한다면 이 온도에서 기 체상태 $\mathrm{CO}_{2}$ 가 유지되는 9기압 이하로 사용압력이 정해져야 하고, 이때 배관두께는 $2.5 \mathrm{~mm}$ 정도면 $\mathrm{DDF}$ 저항에 적합한 것으로 판단된다.

\section{DDF 기준의 적용}

최근 러시아와 시베리아로부터 우리나라까지 가 스배관 연결 사업이 추진되고 있다. 한랭지에 건설 되는 가스배관의 $\mathrm{CVN}$ 값은 낮아서 $\mathrm{DDF}$ 가능성이 크며 이에 대한 대책이 중요하다. 또한 해저가스배 관은 해양플랜트 산업의 중심기술로 떠오르고 있다. 이때 해저 사용조건에서의 $\mathrm{DDF}$ 판정은 설계에 있 어 주요변수로 반드시 고려되어야 할 사항이다.

또한 수소가 관련되는 가스배관에서 $\mathrm{DDF}$ 의 가능 성은 훨씬 커진다. 이것은 배관재질이 수소 취성 현 상과 관련하여 파괴 인성 값의 저하로 이어지기 때 문이다. 미량의 수소도 DDF 가능성을 높일 수 있으 며 이와 같은 수소관련 배관에 $\mathrm{DDF}$ 판정은 매우 중 


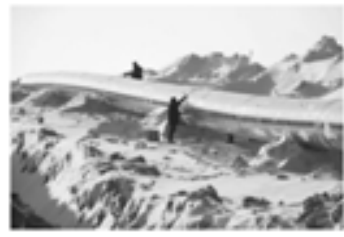

(a)



(c)

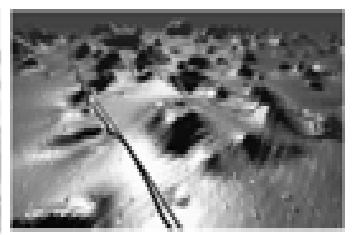

(b)

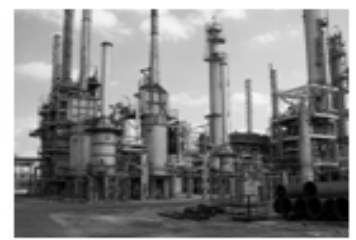

(d)
Fig. 7. Gas pipelines at (a) cold area, (b) under sea area, (c) CCS and (d) SNG system.

요한 요소이므로 이것은 설계기준으로 마련되고 관 리되어야 할 사항이다.

Fig. 7은 이와 같이 $\mathrm{DDF}$ 가 설계기준으로 채택되 어야 할 가스배관을 보여주는 것이다. 여기에는 한 랭지 가스배관, 해저 가스배관, $\mathrm{CO}_{2}$ 배관 및 $\mathrm{SNG}$ 가스배관이 속한다. 즉 차세대 모든 플랜트 산업에 서 가스- 유체 수송라인 배관에 대한 $\mathrm{DDF}$ 판정과 설계기준 마련은 필수적인 것으로 판단된다.

\section{VI. 결 론}

본 연구에서는 기체상태의 $\mathrm{CO}_{2}$ 수송배관의 $\mathrm{DDF}$ 판정기준을 BCTM (Battelle Two Curve Method)식 으로 평가하였으며 이에 대한 주요 결과는 다음과 같다.

1. 기존 천연가스 배관인 $X 70$ 등급(반지름 $381 \mathrm{~mm}$, 두께 $15.9 \mathrm{~mm}$ )을 기체상태의 $\mathrm{CO}_{2}$ 배관으로 사용 한 경우, $\mathrm{DDF}$ 안정성 확보는 충분한 것으로 해 석된다.

2. 기체상태의 $\mathrm{CO}_{2}$ 배관으로 기존 $\mathrm{X70}$ 등급의 가 스배관을 사용할 경우, 상온의 $\mathrm{DDF}$ 안정성 확 보를 위한 배관두께는 $7 \mathrm{~mm}$ 이상 그리고 수송압 력은 $54 \mathrm{bar}$ 이하인 것으로 평가된다.

3. 우리나라 기후조건에서 $\mathrm{CO}_{2}$ 기체 상태를 고려 하면 가스배관 사용조건은 $\left(-40^{\circ} \mathrm{C}, 9\right.$ 기압)으로 한정되고, 이때 X70등급( $381 \mathrm{~mm}$ 반지름)의 $\mathrm{DDF}$ 저항확보가 가능한 최소 배관두께는 $2.5 \mathrm{~mm}$ 로 계산된다

\section{감사의 글}

본 연구는 한국가스공사 2010년 대학협력과제 지 원 연구와 2011년도 강릉원주대학교 장기해외 파견 연구 지원에 의하여 수행되었습니다.

\section{REFERENCES}

[1] T.Harmelen, A.Horssen, M. Jozwicka, "air pollution impacts from carbon capture and storage (ccs)", EEA Technical report, 14 (2011)

[2] S.T. McCoy, E.S. Rubin, "An engineering-economic model of pipeline transport of $\mathrm{CO}_{2}$ with application to carbon capture and storage", Greenhouse Gas Control, 2, 2 (2008)

[3] W.A. Maxey, "Fracture Initiaion, Propagation and Arrest", Paper J Proceedings of Houston, Texas, AGA(1974)

[4] W.A. maxey, F.F. Kiefner, and R.J. Eiber, “Ductile Fracture Arrest in Gas Pipelines", NG-18 Report 100, Texas, AGA(1976)

[5] G. Wilkowski, D. Rudland, H Xu, and N. Sandercon, "Effect of Grade on Ductile Fracnture Arrest Criteria for Gas Pipelines", Proc. Of International Pipeline Conference (2006)

[6] G.D. Fearnehough and D.G. Jones, "Toughness specification for shear fracture arrest in pipelines", International conference on analytical and experimental fracture mechanics (1980)

[7] G.H. Vogt et al, "EPRG Report on toughness for crack arrest in gas pipelins", 3R International, 22, 98 (1983)

[8] F. Bonomo, "A survey and tentative revision of the ductile fracture arrest criterion in pipelines for gas transmission", International conference on analytical and experimental fracture mechanics, Rome (1980)

[9] P.E. O'donoghue, M.F. Kanninen, C.P. Leung, G. Demofonti, S. Venzi, “The development and validation of a dynamic fracture propagation model for gas transmission pipelines", Int. J. Pres. Ves. \& Piping, 70, 11 (1997) 